\title{
Approaches to canine health surveillance
}

\author{
Dan G O'Neill ${ }^{1 *}$, David B Church², Paul D McGreevy ${ }^{3}$, Peter C Thomson ${ }^{3}$ and Dave C Brodbelt ${ }^{1}$
}

\begin{abstract}
Effective canine health surveillance systems can be used to monitor disease in the general population, prioritise disorders for strategic control and focus clinical research, and to evaluate the success of these measures. The key attributes for optimal data collection systems that support canine disease surveillance are representativeness of the general population, validity of disorder data and sustainability. Limitations in these areas present as selection bias, misclassification bias and discontinuation of the system respectively. Canine health data sources are reviewed to identify their strengths and weaknesses for supporting effective canine health surveillance. Insurance data benefit from large and well-defined denominator populations but are limited by selection bias relating to the clinical events claimed and animals covered. Veterinary referral clinical data offer good reliability for diagnoses but are limited by referral bias for the disorders and animals included. Primary-care practice data have the advantage of excellent representation of the general dog population and recording at the point of care by veterinary professionals but may encounter misclassification problems and technical difficulties related to management and analysis of large datasets. Questionnaire surveys offer speed and low cost but may suffer from low response rates, poor data validation, recall bias and ill-defined denominator population information. Canine health scheme data benefit from well-characterised disorder and animal data but reflect selection bias during the voluntary submissions process. Formal UK passive surveillance systems are limited by chronic under-reporting and selection bias. It is concluded that active collection systems using secondary health data provide the optimal resource for canine health surveillance.
\end{abstract}

Keywords: Surveillance, Epidemiology, Canine, Data source, Primary-care practice, Referral practice, Insurance, Questionnaire, Health scheme, Cancer registry, Disorder

\section{Lay summary}

An ability to identify at a population level how many dogs, within breeds or across all breeds develop certain diseases, either over a fixed time period (e.g. each year) or as a proportion of the total population is very important. This helps establish whether some animals and breeds are particularly susceptible to a disease or whether conditions are becoming more or less common. The percentage of affected dogs in a population is called the disease prevalence and the number of new cases of disease in a year is called the disease incidence. These are critical measurements for studying patterns of health and disease and form a branch of medicine called epidemiology. Veterinary epidemiology has been slow to develop but is now recognised as being critical for improving canine health and welfare. To do this effectively, information

\footnotetext{
* Correspondence: doneill@rvc.ac.uk

${ }^{1}$ Veterinary Epidemiology, Economics and Public Health, The Royal Veterinary College, Hawkshead Lane, North Mymms, Hatfield, Herts AL9 7T, UK

Full list of author information is available at the end of the article
}

and health records about dogs, have to be collected. This should be done in a standardised way where the same terms are used to describe diseases and symptoms and laboratory tests. The collection of disease information is described as being health surveillance or disease monitoring. To be effective, systems for doing this should be representative of the whole population. Methods for doing this are now developing but until recently the only ways to collect such information were by using records from pet insurance companies or from veterinary referral clinics. Problems can exist with such data as they can have a selection or referral bias and not truly represent the picture at the population level or include information that is incorrect due to disease misclassification. This review describes the history and development of health surveillance systems in canine medicine and what their strengths and weaknesses are. It also describes some of the new ways this is now being taken forward to collect high quality health data to support clinical and genetic studies. 


\section{Introduction}

Disease surveillance describes the monitoring of population health to ascertain the existence and changes in disease levels in combination with an appropriate mitigation plan once disease levels become inordinate [1-3] and is now an established veterinary activity for disease control [4]. Effective canine health surveillance provides information that supports disorder prioritisation, improved disorder management, focussed clinical research, advice on breed standards reform and regulation to improve animal welfare [5]. Optimal data sources for canine disease surveillance require representativeness of the general population, a welldefined denominator population, validity of disorder diagnosis data and sustainability. Limitations in these areas present as selection bias, misclassification bias and discontinuation of the system respectively [4].

Amongst other epidemiological applications, health surveillance data can be analysed to derive disorder prevalence proportion (proportion of animals affected) and incidence risk (proportion of previously healthy animals that become diseased over a specified period) estimates, perform risk factor (attributes associated with disease occurence) studies and examine survival in affected dogs [1]. Prevalence data are currently available on only $1 \%$ of inherited disorders affecting popular UK dog breeds [6]. A deficiency of disorder prevalence information relating to UK dogs has been identified as a major constraint to effective reforms to purebred dog health [7-9]. Novel epidemiological information on disorders in dogs can assist with welfare prioritisation of disorders for appropriate focus of research efforts and breeding programs $[6,10]$. Increased awareness by veterinarians of disorder frequency and survival can improve diagnostic protocols, optimise case management and enhance prognostic advice given to clients [11].

Collection processes for surveillance data may be passive or active [4]. Passive collection occurs at the discretion of the owner or veterinarian, whose willingness or ability to participate can limit the validity of the emergent data [12]. Passive systems typically suffer from incomplete reporting, selection bias and frequently lack a defined denominator population [13]. Active collection describes systematic data collection methods, usually from a defined population, location and timespan, and can be relatively timely, complete and accurate [13].

Data used to support health surveillance may be primary or secondary. Primary data are collected specifically for the research while secondary data have been pre-collected by a third party for some other reason. Primary data collection offers better control of the types and quality of the data and may be easier to validate. However, secondary data sources may offer more efficient collection, reduced costs, larger sample size, better representativeness and reduced bias [14]. Secondary sources of health data for dogs include pet insurance, referral practice and primary-care practice records [14-16].

Surveillance data may be formatted as unstructured (free-form text), semi-structured (non-standardised lists) or structured data (standardised coding) [17]. Unstructured data are problematic for large-scale studies because of colloquial language, non-standard abbreviations and misspellings $[18,19]$ but may provide contextual information that is otherwise unavailable [20]. Analytic methods for free-form text are progressing [21]. Structured data entry using standardised coding terminologies including the VeNom codes [22] and the AAHA (American Animal Hospital Association) Diagnostic Terms [23] may improve analytic efficiency $[24,25]$.

Obstacles to effective data collection, analysis and interpretation are common to both human and animal surveillance. These include ethical constraints [26], data warehousing [27], setting valid case definitions [28], data quality and missing data [29,30], appropriate coding systems [31], bias [32], generalisability [33], participation [34] linking data sources [35], financial cost [36], clinical coding [37], developing syndromic surveillance [38] and impact assessment [39]. Veterinary surveillance methods can benefit from experiences gained during the development of human methods [40]. Further opportunities for improved veterinary surveillance methods stem from the advent of Big Data techniques for data management, analysis and accessibility [41], and developments in the science of natural language processing (NLP) [42,43].

Diverse data sources have been used to support canine disorder surveillance but there is an absence of a universally-accepted standard for 'good practice' in veterinary surveillance methodology [44]. This review is intended to evaluate current sources of canine health data and to identify their strengths and weaknesses as surveillance sources in order to assist with interpretation of results from studies based on these data.

\section{Review}

\section{Pet insurance databases}

Animal insurance databases have been increasingly used for epidemiological research since the 1970s [45]. A literature review in 2009 of publications based on dog insurance data identified 16 Swedish studies using Agria Insurance data (http://www.agriavet.co.uk/) and three UK studies using PetProtect Insurance data (http://www.petprotect.co.uk/) [15]. About 20 pet insurance providers [46] insure an estimated $34.0-40.3 \%$ of UK dogs [46,47]. In Sweden, $68.4 \%$ of dogs are insured, with $61.0 \%$ of these insured dogs being covered by Agria Pet Insurance [48] alone [49]. Estimates suggest that just $4 \%$ of dogs in Canada [50] and $0.3-3.0 \%$ of dogs in America [51,52] are insured.

For research purposes, insurance databases benefit from holding information on both the numerator clinical 
events and the denominator insured animals across large populations of dogs [15]. Validation studies between Agria Insurance demographic data and veterinary clinical records showed high agreement for dog breed (95\%) and sex (99\%), fair agreement for diagnosis (84\%) but only moderate agreement for year of birth (66\%), suggesting that insurance data are of adequate quality for research purposes [25]. Location information within insurance records allows spatial analysis of geographic risk factors. Post-code data have been used to show associations between the incidence of canine atopic dermatitis and average annual rainfall levels, proximity to a veterinary dermatologist, country sector and increased human population [53].

Although technically easy to analyse [25] and their large size lending statistical power to gain meaningful results even for uncommon breeds [54,55], insurance data have some important limitations. Diagnostic term validity may vary between disorders depending on the ease of clinical diagnosis, the veterinarian's clinical acumen and the veterinary practice's facilities. For example, diagnosis validation for atopic dermatitis claims showed high agreement with veterinary medical records that claim dogs had allergic skin disease $(97.6 \%)$ but only moderate agreement for full atopic dermatitis diagnostic criteria (40.9-84.2\%) [15,56].

Insured dogs may poorly represent the wider national dog population [15]. Insurance coverage varies with breed and purebred status [49] and life-cover may end when dogs reach 10 years of age [57]. Younger animals were heavily overrepresented in a UK insured population [58], requiring age-standardisation of results for generalisation [59]. Insured animals may receive more-frequent veterinary visits and undergo more medical procedures than non-insured animals [15]. A UK study using primary-care practice electronic patient record (EPR) data showed that insured dogs had over twice the odds of a diagnosis of chronic kidney disease compared with uninsured dogs [11]. Insurance status may even affect mortality by impacting on euthanasia decisions [15].

Insurance data include only clinical events that are non-excluded and where the cost exceeds the deductible excess. Exclusions have tended to increase over time and vary by policy, breed and the medical history of individual animals $[15,60]$. Insurance claim levels may also vary between breeds. For example, death claims with an associated diagnosis were received for just $50 \%$ of insured crossbred dogs compared with over $80 \%$ of insured Bernese Mountain Dogs and Cavalier King Charles Spaniels [15]. Cohort insurance studies to monitor health status within individual animals over time can be problematic because repeat-disorder claim levels are affected by changing insurance status and dynamic exclusions applied over time based on claim history [61].
Insurance data research has lead to many useful publications on dogs covering specific disorders and overall morbidity and mortality (Table 1). Good understanding and interpretation of limiting factors are important when considering insurance data for canine health surveillance. Proposed studies should be considered on an individual basis or possibly even abandoned in the case of unavailable or inaccurate data [15]. Swedish insurance studies have benefited from an open approach to data sharing and strong research collaboration between Agria Insurance and academic colleagues that could be mirrored in other countries [55].

\section{Referral practice clinical records}

The Veterinary Medical Data Base (VMDB) holds 7 million standardised abstracted records from 26 veterinary schools in the US and Canada [75] with a coding system that records diagnostic terms using either pathophysiologic, histologic or descriptive terminologies [76]. VMDB data mining is based on discrete factors including breed, age, sex and diagnostic code and non-associated institutions are charged for data searches.

The large study population lends high statistical power to VMDB analyses, enabling exploration of rare disorders or disorder-within-breed studies [12] such as thyroid cancer, $0.2 \%$ prevalence [77], discospondylitis, $0.2 \%$, [78], bronchiectasis, 0.05\%, [79] and leptospirosis, 0.04\% [80]. Other prevalence studies that used VMDB data have investigated cataract [81], glaucoma [81] and cardiac tumours [82]. However, VMDB studies are limited by inconsistencies in data completeness and quality, and by the mixing of referral data with some primary-care data [15]. Only nine of the contributing universities use the structured SNOMED coding system that links clinical care events to terms selected from a comprehensive list of disorder concepts and descriptions [83,84]. The currency of the VMDB data is low, given that just 14 universities have uploaded data since the year 2000 [12,75].

Referral data spanning 1995-2010 from the University of California-Davis Veterinary Medical Teaching Hospital were analysed to report purebred dog predispositions to 24 inherited disorders [85]. The authors considered that more intensive evaluation within breeds with published disorder predisposition and increased willingness of owners of purebred dogs to spend heavily on clinical investigations may lead to over-representation of some disorders in specific breeds and in purebreds more generally [86].

Despite the promise of good reliability for diagnoses from referral clinical data, referral biases towards complicated cases requiring more specialised care and towards locations closer to specialist centres limit the generalisability of study results [12]. Clients and animals that are referred are filtered by diagnostic work-ups, insurance status and financial considerations $[15,87]$. Referral bias is likely to 
Table 1 Selected published and findings studies on dog health based on insurance data

\begin{tabular}{|c|c|c|c|}
\hline Topic \& main conclusion & Insurer & Country & Reference \\
\hline German Shepherd Dog, predisposed to immune-mediated diseases & Agria $^{a}$ & Sweden & Vilson et al. [62] \\
\hline Atopic dermatitis, offspring of bitches fed non-commercial diet during lactation protected & Agria $^{a}$ & Sweden & Nodtvedt et al. (2007) [53] \\
\hline Bone tumours, Irish Wolfhound, St. Bernard, and Leonberger at increased risk & Agria $^{a}$ & Sweden & Egenvall et al. (2007) [63] \\
\hline Cancer, skin and soft tissue tumours had highest prevalence & PetProtect ${ }^{b}$ & UK & Dobson et al. (2002) [58] \\
\hline Demography, insured dogs similar to the general dog population & Agria $^{a}$ & Sweden & Sallander (2001) [64] \\
\hline $\begin{array}{l}\text { Diabetes mellitus, highest incidence in Australian Terrier, Samoyed, Swedish Elkhound } \\
\text { and Swedish Lapphund }\end{array}$ & Agria $^{a}$ & Sweden & Fall et al. (2007) [65] \\
\hline Dystocia/caesarean section, Scottish terrier at increased risk & Agria $^{a}$ & Sweden & Bergstrom (2006) [66] \\
\hline $\begin{array}{l}\text { Heart disease, Irish Wolfhound, Cavalier King Charles Spaniel and Great Dane showed highest } \\
\text { mortality }\end{array}$ & Agria $^{a}$ & Sweden & Egenvall et al. (2006) [67] \\
\hline $\begin{array}{l}\text { Intervertebral disc degeneration, Miniature Dachshund, Standard Dachshund and Doberman } \\
\text { Pinscher had highest incidence }\end{array}$ & Agria $^{\mathrm{a}}$ & Sweden & Bergknut et al. (2012) [68] \\
\hline Lymphoma, Bull mastiff, Bulldog and Boxer had high incidence & PetProtect ${ }^{b}$ & UK & Edwards et al. (2003) [69] \\
\hline Mammary tumours, highest incidence in English Springer Spaniel, Doberman and Boxer & Agria $^{a}$ & Sweden & Egenvall et al. (2005b) [70] \\
\hline Morbidity and mortality, marked breed differences in survival & Agria $^{a}$ & Sweden & $\begin{array}{l}\text { Bonnett and Egenvall (2010) } \\
\text { [55] }\end{array}$ \\
\hline Morbidity and mortality (1995-1996), insurance data useful for epidemiological studies & Agria $^{a}$ & Sweden & Egenvall et al. (2000a) [60] \\
\hline Mortality, wide breed differences in survival & Agria $^{\mathrm{a}}$ & Sweden & Egenvall et al. (2000b) [71] \\
\hline Mortality, $>40 \%$ of deaths from trauma, tumours and locomotor disorders & Agria $^{a}$ & Sweden & Bonnett et al. (1997) [72] \\
\hline Mortality (1995-2000), Irish Wolfhound and Great Dane had highest mortality & Agria $^{a}$ & Sweden & Egenvall et al. (2005a) [57] \\
\hline $\begin{array}{l}\text { Mortality (1995-2000), } 62 \% \text { of deaths from tumour, trauma, locomotor, heart and } \\
\text { neurological disorders }\end{array}$ & Agria $^{a}$ & Sweden & Bonnett et al. (2005) [73] \\
\hline $\begin{array}{l}\text { Pyometra, increased risk Rough Collies, Rottweilers, Cavalier King Charles Spaniels, Golden } \\
\text { Retrievers, Bernese Mountain Dogs, and English Cocker Spaniels }\end{array}$ & Agria $^{a}$ & Sweden & Egenvall et al. (2001) [74] \\
\hline
\end{tabular}

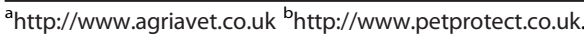

vary between disorders and to compromise the validity of prevalence studies that compare multiple disorders [12]. An ill-defined denominator population containing few healthy animals further limits referral data for prevalence estimation [88]. Referral clinical datasets may be less reliable for generalisable prevalence estimation and may be best reserved to test hypotheses relating to specific causal mechanisms [89].

\section{Primary-care practice clinical records}

Analysis of primary-care practice data benefits from the cumulative clinical experience of general practitioners to offer unique insights into companion animal health [24] and can support an evidence-based approach that is relevant to primary-care practitioners [90].

An early example of primary-care practice surveillance (1998-2001) used manual paper-based data collection by veterinary students undergoing extramural studies to describe overall reasons for veterinary presentation and the prevalence of dermatological diagnoses [91]. This study concluded that, although practicable for short-term and highly focused studies, clinical research using paper-based records was highly labour-intensive and unsustainable for long-term studies.
Electronic recording of clinical data is now central to human and animal healthcare [92,93]. Data collected from the $90 \%$ of UK veterinary practices that use electronic practice management systems (PMSs) can contribute enormously to clinical research [94-96]. The 'Independent Inquiry into Dog Breeding' report cited primary-care practice electronic clinical data using standardised coding of diagnoses as the optimal data source for reliable prevalence estimation [7]. However, early attempts at large-scale electronic surveillance struggled to cope with the large volumes of clinical data collected [19] and initial veterinary PMSs did not enforce structured coding systems [97], although there is now evidence that practising veterinarians accept a clinical rationale for standardised data recording $[98,99]$.

In the US, the National Companion Animal Study (NCAS) spanned 1992-1995 and analysed coded clinical data from 31,484 dogs treated at 52 first-opinion clinics [5]. Clinical diagnostic terms were recorded onto paper by attending clinicians before codification to a standardised nomenclature (PetTerms; developed dynamically during the study) and electronic transfer to a proprietary PMS [100].

The first of three published NCAS studies described age, breed, sex, diet and body condition score, and reported 
prevalence estimates for the most common disorders diagnosed [5]. However, the study was compromised by limiting the denominator population to just those animals with at least one coded diagnosis $(36.3 \%$ of unique animal records), potential transcription error during the paper-to-electronic transfer of data and the absence of a prior-standardised coding system. Two further NCAS publications on obesity in cats [101] and dogs [102] demonstrated the potential to augment secondary EPR data with additional primary data collection on diet and body condition score for enhanced investigations [103]. The NCAS studies highlighted the importance to sustainable surveillance of standardised coding, direct recording of electronic data by clinicians, inclusion of all clinical care events and electronic integration between PMSs and research databases.

Eight hundred Banfield Pet Hospitals (http://www. banfield.com/) have generated clinical data on over 2.2 million dogs across 43 states in the USA [104]. Surveillance based on Banfield clinical data benefits from the use of a single PMS with daily uploads of standardised EPRs to a single computer server [105]. Collaborative studies using Banfield Pet Hospital data have reported on canine disorders including nematode parasitism, demodicosis, pancreatitis and atopic dermatitis (Table 2) while internal Banfield studies have been published online as 'State of Pet Health' reports [104].

The National Companion Animal Surveillance Program (NCASP) was developed at Purdue University in 2003 with a \$1.2 million grant from the Centers for Disease Control and Prevention $(\mathrm{CDC})$ to provide near real-time syndromic surveillance of pet animals as sentinels for bioterrorism, emerging zoonoses, toxic chemical exposures and for veterinary drug and vaccine pharmacovigilance [116]. Banfield EPR data were linked with Antech Diagnostics electronic laboratory reports from over 18,000 private veterinary practices [117]. Resultant publications on dog health have covered vaccine safety $[19,107,118,119]$, tick infestation [108] and toxic exposure [115]. However, NCASP surveillance was limited by confidentiality issues, delayed dissemination of results and difficulties in managing such large volumes of data [117]. It is reported that NCASP has been discontinued [120].

VetCompass (Veterinary Companion Animal Surveillance System) was developed at the Royal Veterinary College (RVC) in collaboration with the University of Sydney for companion animal surveillance using primary-care practice clinical data. A pilot phase, spanning 2007-2009, preceded implementation of the full UK project from September 2009 onwards. VetCompass holds clinical data on over 275,000 dogs from 189 UK practices (August 2013) (http://www.rvc.ac.uk/VetCompass/Index.cfm). Attending clinicians record VeNom code [22] summary diagnosis terms during episodes of clinical care [121]. Clinical data are automatically uploaded weekly to the VetCompass database [122]. Published VetCompass studies have covered pharmacotherapeutics [122], demography [123] and specific disorders [11,121] of dogs. Current VetCompass projects aim to prioritise the welfare impact of common disorders in dogs, to evaluate the longitudinal course of canine mitral valve disease and to pilot the linkage of pedigree data to clinical health records in collaboration with the UK Kennel Club (KC) [47]. VetCompass has been developed in Australia and preliminary project work is underway in Spain, Germany and New Zealand. Realisation of the full surveillance potential of VetCompass has been constrained by limitations in automated information extraction from large datasets but current work to apply NLP methods offers promise [124].

Table 2 Selected publications and findings on dog health based on Banfield Pet Hospital clinical data

\begin{tabular}{lcc}
\hline \multicolumn{1}{c}{ Topic } & Study period & Reference \\
\hline Gonadectomy, is a risk factor for obesity & $1998-2010$ & Lefebvre et al. [106] \\
Vaccine-associated adverse events, multiple vaccines doses administered per visit increased risk & $2002-2003$ & Moore et al. [107] \\
Tick infestation, younger, male and sexually intact dogs at increased risk & $2002-2004$ & Raghavan et al. [108] \\
Periodontal disease, associated with cardiovascular-related conditions & $2002-2006$ & Glickman et al. [109] \\
Periodontal disease, positive association with the incidence of azotaemic CKD & 2002-2008 & Glickman et al. [110] \\
Nematode parasitism, age, body weight, sex, breed and geographic region were risk factors & $2003-2006$ & Mohamed et al. [111] \\
Tick infestation, systematic monitoring of veterinary and human medical data can improve detection & $2006-2007$ & Rhea et al. [103] \\
in tick activity & 2006 & Lewis [112] \\
Pancreatitis, prevalence of 23 per 10,000 patients & 2006 & Plant et al. [105] \\
Demodicosis, American Staffordshire Terrier, Staffordshire Bull Terrier and Chinese Shar-pei at highest risk & 2007 & Lund [113] \\
Atopic dermatitis, 1.7\% prevalence & 2007 & Trevejo et al. [114] \\
Castration, 64\% prevalence & 2006 & Maciejewski [115] \\
Environmental monitoring, methods using veterinary records require further development & &
\end{tabular}


The Small Animal Veterinary Surveillance Network (SAVSNET) was launched in 2008 at the University of Liverpool as a pilot project collecting data from UK veterinary diagnostic laboratories and veterinary practices [125] before becoming a registered charity in 2012 and entering a partnership with the British Small Animal Veterinary Association (BSAVA) [126]. A SAVSNET study of antibacterial prescribing patterns identified the importance of data validation for automated search strategies of primary-care practice data by showing substantial variation between the positive predictive value of four diagnoses, abscess (82\%), diarrhoea (91\%), cystitis (100\%) and coughing (90\%) [127]. A moderate negative impact from using opt-in consent was indicated by the $2.6 \%$ of clients who declined to participate [127], suggesting the relevance of appropriate consent protocols within project design [128]. Syndromic surveillance results are also posted on the project website [129].

The Centre for Evidence-based Veterinary Medicine (CEVM) was established in 2009 at the University of Nottingham [130]. The CEVM aims to promote the use of reliable and relevant science (or evidence) in clinical decision-making between veterinary surgeons and the owners of the animals. To facilitate this, the CEVM has created a small network of sentinel practices who they work very closely with, to look at the complexity of consultations, the reliability and limitations of EPRs and identify important areas for future research for veterinarians, owners and their animals.

To-date, primary-care practice EPR data have been an under-used surveillance resource [5]. Studies using EPR data may encounter misclassification problems [127] and technical difficulties related to management and analysis of large datasets [120]. Additionally, primary-care veterinary data mainly feature disorders that either prompted a veterinary-care visit or were detected during an otherwise veterinary examination and thus may miss that proportion of the overall disorder burden of dogs that does not receive veterinary attention. Just $44.1 \%$ of the true illness events in dogs are severe or persistent enough to lead to veterinary attention [131]. However, primarycare EPR research boasts increasingly large datasets for achieving good precision within study output [132] and the investigation of rare events [133], good prospects of generalisation to the wider dog population from the $70 \%$ of UK dogs that are registered with a veterinary practice $[33,46]$ and clinical relevance of the emergent results to practising veterinarians [127]. Cohort data collection can facilitate survival and co-morbidity analyses for chronic diseases [11,134]. Ongoing developments in database management, analytic techniques, standardised coding and collaborative research design should enhance the surveillance role for primary-care practice EPR research [13].

\section{Veterinary cancer registries}

Cancer registries systematically collect and analyse cancer data and are considered key to human cancer control, with 449 registries covering $21 \%$ of the world human population [135]. However, veterinary cancer registries are uncommon, often short-lived and suffer from poor communication and collaboration [136].

The VMDB began in 1964 as a hospital-based cancer registry [75,137] and has published studies in dogs that covered cutaneous mast cell tumours [138], prostate carcinoma [139], cardiac tumours [82] and osteosarcoma [140]. Referral bias limits generalisability from VMDB study results to the wider dog population [12].

The Norwegian Canine Cancer Registry (NCCR) was established in 1990 and has reported results from studies that investigated mammary tumours in bitches [141,142]. The Danish Veterinary Cancer Registry (DVCR) was established in 2005 as an online registry for passive veterinarian upload of clinical information [137]. Published DVCR studies have included cancer frequency in dogs in Denmark [143] and canine mast cell tumours [144]. The Animal Tumour Registry of Vicenza and Venice (Italy) was established in 2005 and used data on 2,509 samples submitted by 164 veterinary clinics to report cancer incidence in dogs. A denominator dog population was estimated using a telephone survey [145]. The Animal Tumour Registry of Genoa (Italy) used data from 6,743 canine tumour biopsies submitted between 1985 and 2002 to report cancer incidence in dogs. A denominator population was estimated using a capture-recapture methodology [146]. These studies acknowledged limitation from poor denominator population enumeration and used differing methods to estimate missing values. The telephone survey for population estimation benefitted from relative speed and additional collection of other useful demographic data.

Although useful for some risk factor studies, cancer registry clinical data are limited for disease surveillance in dogs by variable reporting, referral bias, denominator population enumeration problems and geographical variation $[12,147]$. While under-reporting might generally be expected, cancer registries may also over-report certain neoplasias because of screening programs, research focus, new diagnostic modalities or free histopathology. Inconsistent inclusion criteria, nomenclature and classification schemes have limited comparisons of results across schemes. The use of standardised coding and diagnostic systems, data extraction directly from PMSs and cross-linking with pathology laboratory systems would enhance the application of veterinary cancer registry data for disease surveillance.

\section{Questionnaire-based data collection}

Registered breeders represent a knowledgeable and important sub-population of dog-owners. The KC/BSAVA 
UK health survey of purebred dogs collected information from breeders on overall dog health, breeding and mortality as well as puppy birth defects. Of approximately 56,363 questionnaires forwarded to breed club members, 13,759 useable forms were returned (24\%), representing 36,006 live dogs [148]. This large survey provided a useful resource of information on purebred dog health and mortality but generalisation was limited by the low response rate, absence of veterinary validation of reported disorders and inclusion of only those dogs owned by breed club members. Future studies aimed at breeder groups could benefit from linkage to veterinary diagnoses and greater prior involvement of breed clubs.

Information collected directly from the dog-owning public may improve representativeness of the overall dog population. The Pet Food Manufacturers Association (PFMA) 2012 survey used data from 2,159 face-to-face interviews to report demographic estimates for the UK dog population [149]. However, the lack of reporting on response rates, selection criteria, statistical weightings and confidence intervals limit the validity of the PFMA survey results. A UK general public telephone survey investigating dog ownership achieved a response rate $37 \%$ from a total of 1,656 calls and reported that $23.92 \%$ of households owned at least one dog [46]. A random-digit dialling telephone survey in Ireland generated 1,250 completed responses from 105,803 calls (1.2\%) to describe dog and cat demography but was limited by the low completion rate [150].

Veterinary practice questionnaires can collect data from either the practice teams or their clients. A questionnaire circulated by email and post to 2,763 UK veterinary practices was used to report the number of practice-registered dogs but was limited by a low response rate (3.7\%) [46]. A questionnaire distributed at UK veterinary clinics and dog shows investigating inter-dog aggression reported a completion rate of 3,897 from 14,566 distributed questionnaires (26.8\%) [151]. An Australian study distributed questionnaires at veterinary clinics and pet shops to investigate owners' attitudes towards obesity in dogs and reported a $36.5 \%$ response rate [152]. Integration of owner-recorded data offers the potential to complement veterinarian-derived data within broader study designs.

Questionnaire surveys are common methods for active collection of primary veterinary epidemiological data [153] and benefit from relative speed, repeatability, low cost and the capture of information on multiple risk factors and confounders. However, potential drawbacks associated with the use of questionnaires include low response rates, loss of information on temporality, difficulties with data validation, recall and non-responder bias, and ill-defined denominator populations [154]. Participation in questionnaire-based studies have been declining by about 1\% annually from 1970 to 2003 because of generally decreased volunteerism, over-surveying, increasingly complicated surveys and conversion from landline to mobile phone use [155]. That said, increasing internet access has enhanced the promise for internet-based questionnaires [156] and careful study design can mitigate some of these drawbacks. Study designs that include nested questionnaires can benefit from focused primary data collection.

\section{Canine health schemes}

Over 120 dog breeds have at least one DNA test available [157]. The results of formal DNA screening schemes co-ordinated by the $\mathrm{KC}$ are published online, providing surveillance data that can be linked with $\mathrm{KC}$ pedigree information on phenotype and parentage [158]. These data have been analysed to estimate the mutation prevalence for primary lens luxation among affected breeds [159]. However, selection bias arising from systematic avoidance of or intensive testing of known affected lines have limited generalisation from these studies to the wider dog population [160].

Brain stem auditory evoked response (BAER) testing distinguishes bilaterally and unilaterally hearing-impaired dogs from non-affected animals [161]. BAER data have been used to report prevalence estimates for deafness in Dalmatians [162], Border Collies [163] and Australian Cattle Dogs [164] as well as across multiple breeds [165]. These studies benefitted from well-defined case inclusion criteria and large study sizes but the voluntary submission process may have affected the presentation probabilities for known deaf individuals.

The BVA (British Veterinary Association)/KC hip dysplasia (HD) and elbow dysplasia (ED) schemes hold data on over 100,000 radiographs assessed since 1984. Dogs evaluated under these schemes must be permanently identified by microchip or tattoo [166] and breed median scores are published to assist breeding decisions [167]. Linkage between $\mathrm{HD}$ and ED schemes results and $\mathrm{KC}$ pedigree data has allowed pedigree evaluation and generation of estimated breeding values (EBVs) [168] for HD [169] and ED [170] in Labrador Retrievers. However, selection bias resulting from predominant inclusion of registered purebreds and the unlikelihood of submissions from dogs that are clinically affected or have obviously affected radiographs limit generalisation and may bias prevalence estimates downwards [171].

The BVA/KC/ISDS (International Sheepdog Society) eye scheme holds eye test data spanning over 30 years of testing for 11 hereditary eye conditions in over 50 breeds [172]. These data have been analysed to estimate the incidence [173] and inheritability [174] of multifocal retinal dysplasia in the Golden Retriever and the incidence of cataracts among Labrador Retrievers [175]. Eye scheme data for research are limited by misclassification bias from 
Table 3 Advantages and limitations to data sources used for health surveillance in dogs

\begin{tabular}{|c|c|c|c|}
\hline Data source & Advantages & Limitations & Applications \\
\hline \multirow[t]{4}{*}{ Pet insurance databases } & Large size & Difficult to validate & $\begin{array}{l}\text { Agria Pet Insurance data analysis } \\
\text { in Sweden [15] }\end{array}$ \\
\hline & Defined denominator & $\begin{array}{l}\text { Questionable representativeness of the } \\
\text { general population }\end{array}$ & \multirow[t]{3}{*}{$\begin{array}{l}\text { Pet Protect insurance data analysis } \\
\text { in UK }[58,69]\end{array}$} \\
\hline & $\begin{array}{l}\text { High reliability for breed } \\
\text { and sex }\end{array}$ & \multirow[t]{2}{*}{$\begin{array}{l}\text { Loss of data on low-cost or excluded } \\
\text { disorders }\end{array}$} & \\
\hline & Coded diagnoses & & \\
\hline \multirow[t]{3}{*}{ Referral practice clinical records } & Good diagnostic reliability? & Referral bias & \multirow{3}{*}{$\begin{array}{l}\text { Veterinary Medical Data Base } \\
\text { (VMDB) [75] }\end{array}$} \\
\hline & Coded diagnoses? & Poorly defined denominator & \\
\hline & Large databases & Poorly representative & \\
\hline \multirow[t]{6}{*}{ Primary-care practice clinical records } & Large databases & Diagnostic reliability? & Banfield Pet Hospital [104] \\
\hline & Highly representative? & Technical complexities & NCAS [5] \\
\hline & Coded diagnoses & \multirow[t]{4}{*}{ Only events with veterinary care } & NCASP [116] \\
\hline & Defined denominator & & VetCompass [47] \\
\hline & Generalisability & & SAVSNET [129] \\
\hline & & & CEVM [130] \\
\hline \multirow[t]{3}{*}{ Veterinary cancer registries } & Human registries common & Referral bias & $\begin{array}{l}\text { Veterinary Medical Data Base } \\
\text { (VMDB) [75] }\end{array}$ \\
\hline & \multirow[t]{2}{*}{ Good diagnostic reliability } & Poorly defined denominator & \multirow{2}{*}{$\begin{array}{l}\text { Danish Veterinary Cancer } \\
\text { Registry [137]. }\end{array}$} \\
\hline & & Poorly representative & \\
\hline \multirow[t]{3}{*}{ Questionnaire-based data collection } & Relatively inexpensive & Response rate & \multirow{3}{*}{$\begin{array}{l}\text { The KC/BSAVA UK health survey of } \\
\text { purebred dogs [148]. }\end{array}$} \\
\hline & Flexible & Difficult to validate & \\
\hline & $\begin{array}{l}\text { Can nest within other } \\
\text { study designs }\end{array}$ & Loss of information on temporality & \\
\hline \multirow[t]{4}{*}{ Canine health schemes } & Large databases & Poorly representative & $\begin{array}{l}\text { BVA/KC hip dysplasia and elbow } \\
\text { dysplasia scheme [194] }\end{array}$ \\
\hline & Diagnostic reliability & Selection bias & $\begin{array}{l}\text { BVA/KC elbow dysplasia } \\
\text { scheme [195] }\end{array}$ \\
\hline & $\begin{array}{l}\text { Linkage to KC pedigree } \\
\text { data }\end{array}$ & & The BVA/KC/ISDS eye scheme [172]. \\
\hline & $\begin{array}{l}\text { Permanent animal } \\
\text { identification }\end{array}$ & & \\
\hline \multirow{4}{*}{$\begin{array}{l}\text { Other companion animal surveillance } \\
\text { systems in the UK }\end{array}$} & \multirow[t]{4}{*}{ Relatively inexpensive } & Under-reporting & \multirow[t]{2}{*}{ SARSS [176] } \\
\hline & & Poorly defined denominator & \\
\hline & & Selection bias & DACTARI [186] \\
\hline & & Poor generalisability & CICADA [189] \\
\hline
\end{tabular}

diagnosis difficulties for ocular disorders and selection bias from testing only a small proportion of $\mathrm{KC}$-registered purebreds and very few non-registered dogs [173].

Canine health schemes generally harvest primary data from voluntary owner submissions and often benefit from well-characterised data, permanent animal identification (microchip, tattoo), openly published results and linkage with genetic databases [166]. However, intrinsic selection bias from passive collection processes and questionable representation of the overall dog population limit the generalisability of study results.
Other companion animal surveillance systems in the UK SARSS, Suspected Adverse Reaction Surveillance Scheme Veterinary pharmacovigilance in the UK is monitored by the Veterinary Medicines Directorate (VMD) via SARSS using passive reporting of adverse events to veterinary medicines in both animals and humans [176]. The number of adverse events reported per year for dogs increased from 653 to 1,615 between the years 2003 to 2011 [177-185]. The 2011 result [182] equates to an average of only one report per year for every 10 of the 17,260 registered home-practising veterinary surgeons in the UK [95]. This 
suggests heavy under-reporting and likely selection bias with resultant questionable reliability of SARRS data for general surveillance purposes.

\section{DACTARI, The Dog and Cat Travel and Risk Information}

The DACTARI surveillance scheme was launched in 2003 by the Department for Environment Food and Rural Affairs with involvement from BVA and BSAVA as a national voluntary reporting scheme to monitor exotic diseases events in dogs and cats in Great Britain [186]. The scheme focuses on four disorders: leishmaniosis, babesiosis, ehrlichiosis and dirofilariasis. However, from 2001 to 2011, only 109 reports were received for these four diseases in dogs. Given that Bristol University reported 257 cases of canine leishmaniosis in the UK between 2005 and 2007 [187], this suggests heavy under-reporting to DACTARI of the true exotic disease burden.

\section{CICADA, The Companion Animal Disease Survey}

The CICADA survey is coordinated by MSD Animal Health (http://www.msd-animal-health.co.uk/) as a UK web-based disease surveillance scheme with voluntary online submissions of animal health data by veterinarians and professional organisations. The scheme aims to report disease trends, recent outbreaks and current hot spots [188]. Between October 2011 and June 2012, only 93 institutions (laboratories, universities or veterinary practices) submitted information to CICADA [189], suggesting high selection bias and limited generalisability to the wider animal population.

Rather than being useful for general surveillance, passive reporting systems may better suited for generating alarm signals that trigger more intensive targeted surveillance [19]. Passive collection may suffer from chronic under-reporting, inadequately defined denominator populations, selection bias and poor generalisation, and such systems are difficult to sustain in the long-term [190].

\section{Conclusions}

Increasing demand for veterinary surveillance is constrained by decreasing availability of human and financial resources [191]. Credible canine health surveillance requires a reliable data source with a well-defined denominator population, evidence of representativeness and validity and appropriate study design [4]. Active data collection is preferred for veterinary surveillance because of reduced selection bias and known selection probability for each epidemiological unit that permit estimation of absolute, rather than relative, risk values [2]. Secondary data are becoming increasingly important for companion animal surveillance because of their collection efficiency, reduced costs, larger sample size, better representativeness and reduced bias [14]. Integration between data sources can facilitate knowledge extraction and interpretability within individual studies and underlines the epidemiological importance of permanent identification of individual animals [192,193].

Many data sources have been recruited for canine health surveillance, each with distinct prevailing advantages and limitations (Table 3). Insurance data benefit from large and well-defined denominator populations but are limited by selection bias relating to the clinical events claimed and animals covered. Veterinary referral clinical data offer good reliability for diagnoses but are limited by referral bias for the disorders and animals referred. Primary-care practice EPR data benefit from strong alignment with the general dog population and veterinary validation but encounter technical difficulties related to the management and analysis of large datasets. Veterinary cancer registries offer good diagnostic reliability but may have ill-defined denominator populations and poor representativeness. Questionnaire surveys are relatively inexpensive and collect primary data but suffer from issues relating to validation and response rates. Canine health scheme data benefit from well-characterised disorder and animal data but are subject to selection bias from the voluntary submission process. Formal UK passive surveillance systems are limited by chronic under-reporting and selection bias. It is concluded that active collection systems using secondary health data currently provide the optimal single resource for canine health surveillance and that linking multiple data sources can substantially amplify the research potential.

\section{Abbreviations}

AAHA: American Animal Hospital Association; BSAVA: British Small Animal Veterinary Association; BVA: British Veterinary Association; CDC: Centers for Disease Control and Prevention; CEVM: The Centre for Evidence-based Veterinary Medicine; CICADA: Companion Animal Disease Survey; DACTARI: Dog and Cat Travel and Risk Information; DVCR: Danish Veterinary Cancer Registry; EBV: Estimated breeding value; ED: Elbow dysplasia; EPR: Electronic patient record; HD: Hip dysplasia; ISDS: International Sheepdog Society; KC: The Kennel Club; NCAS: National Companion Animal Study; NCASP: National Companion Animal Surveillance Program; NCCR: Norwegian Canine Cancer Registry; PFMA: Pet Food Manufacturers Association; PMS: Practice management systems; RVC: Royal Veterinary College; SARSS: Suspected Adverse Reaction Surveillance Scheme; SAVSNET: Small Animal Veterinary Surveillance Network; VetCompass: Veterinary Companion Animal Surveillance System; VMD: Veterinary Medicines Directorate; VMDB: Veterinary Medical Database.

\section{Competing interests}

All authors of this review are involved in the development of the VetCompass Surveillance System which collects and studies primary-care veterinary clinical data [47]

\section{Authors' contribution}

DON, is the primary author for the current work and was involved in the conception, design, data collection and drafting of the manuscript. DC, contributed to the conception and design of the work, and helped to draft and revise the manuscript. PM, contributed to the conception and design of the work, and helped to draft and revise the manuscript. PT, contributed to the conception and design of the work, and helped to draft and revise the manuscript. DB, was involved in the conception, design, data collection, drafting and revising of the manuscript. All authors read and approved the final manuscript. 


\section{Acknowledgements}

Funding support by the Royal Society for the Prevention of Cruelty to Animals (RSPCA) for this study is acknowledged. Editing assistance from Cate Webb is gratefully acknowledged.

\section{Author details}

${ }^{1}$ Veterinary Epidemiology, Economics and Public Health, The Royal Veterinary College, Hawkshead Lane, North Mymms, Hatfield, Herts AL9 7T, UK. ${ }^{2}$ Small Animal Medicine and Surgery Group, The Royal Veterinary College, Hawkshead Lane, North Mymms, Hatfield, Herts AL9 7TA, UK. ${ }^{3}$ Faculty of Veterinary Science, The University of Sydney, R.M.C. Gunn Building (B19), Sydney, NSW 2006, Australia.

Received: 30 October 2013 Accepted: 14 January 2014

Published: 16 April 2014

\section{References}

1. Thrusfield M: Veterinary Epidemiology. Oxford: Blackwell Publishing; 2007:610.

2. Salman MD: Animal disease surveillance and survey systems, methods and applications. Ames lowa: lowa State Press, Blackwell; 2003. 222 p.

3. Salman MD: Surveillance tools and strategies for animal diseases in a shifting climate context. Animal health research reviews; 2013.

4. Doherr MG, Audigé L: Monitoring and surveillance for rare health-related events, a review from the veterinary perspective. Philosophical transactions of the Royal Society of London Series B, Biological sciences 2001, 356:1097-1106.

5. Lund EM, Armstrong PJ, Kirk CA, Kolar LM, Klausner JS: Health status and population characteristics of dogs and cats examined at private veterinary practices in the United States. J Am Vet Med Assoc 1999, 214:1336-1341.

6. Collins LM, Asher L, Summers J, McGreevy P: Getting priorities straight, risk assessment and decision-making in the improvement of inherited disorders in pedigree dogs. Vet J 2011, 189:147-154

7. Bateson P: Independent inquiry into dog breeding. Cambridge: University of Cambridge; 2010.

8. Rooney N, Sargan D: Pedigree dog breeding in the UK, a major welfare concern? West Sussex, RSPCA: Horsham; 2008.

9. APGAW: A healthier future for pedigree dogs. London: The Associate Parliamentary Group for Animal Welfare; 2009.

10. McGreevy PD: Breeding for quality of life. Anim Welf 2007, 16:125-128.

11. O'Neill DG, Elliott J, Church DB, MCGreevy PD, Thomson PC, Brodbelt DC: Chronic kidney disease in dogs in UK veterinary practices, prevalence, risk factors, and survival. J Vet Intern Med 2013, 27:814-821.

12. Bartlett PC, Van Buren JW, Neterer M, Zhou C: Disease surveillance and referral bias in the veterinary medical database. Preventive Veterinary Medicine 2010, 94:264-271.

13. Moore GE, Lund E: Disease reporting and surveillance, where do companion animal diseases fit in? Vet Clin N Am Small Anim Pract 2009, 39:225-240

14. Sorensen HT, Sabroe S, Olsen J: A framework for evaluation of secondary data sources for epidemiological research. Int J Epidemiol 1996, 25:435-442.

15. Egenvall A, Nødtvedt A, Penell J, Gunnarsson L, Bonnett BN: Insurance data for research in companion animals, benefits and limitations. Acta Vet Scand 2009, 51:42.

16. Buring JE: Primary data collection, what should well-trained epidemiology doctoral students be able to do? Epidemiology 2008, 19:347-349.

17. Resnik P, Niv M, Nossal M, Kapit A, Toren R: Communication of clinically relevant information in electronic health records, a comparison between structured data and unrestricted physician language; 2008. Fall.

18. Zhou B: Keyword Search on Large-Scale Structured, Semi-Structured, and Unstructured Data. In Handbook of Data Intensive Computing. Edited by Furht B, Escalante A. New York: Springer; 2011:733-751.

19. Moore GE, Frana TS, Guptill LF, Ward MP, Lewis HB, Glickman LT: Postmarketing surveillance for dog and cat vaccines, new resources in changing times. J Am Vet Med Assoc 2005, 227:1066-1069.

20. Liao KP, Cai T, Gainer V, Goryachev S, Zeng-treitler Q, Raychaudhuri S, Szolovits P, Churchill S, Murphy S, Kohane I, Karlson EW, Plenge RM: Electronic medical records for discovery research in rheumatoid arthritis. Arthritis Care Res 2010, 62:1120-1127.

21. Lam K, Parkin T, Riggs C, Morgan K: Use of free text clinical records in identifying syndromes and analysing health data. Vet Rec 2007, 161:547-551.
22. The VeNom Coding Group: In VeNom Veterinary Nomenclature. Edited by Group TVC; 2013. http://www.venomcoding.org/VeNom/Welcome.html, VeNom Coding Group

23. AAHA: AAHA Diagnostic Terms. American Animal Hospital Association; 2013. https://www.aahanet.org/Library/Diagnostic.aspx

24. Faunt K, Lund E, Novak W: The power of practice, harnessing patient outcomes for clinical decision making. Vet Clin N Am Small Anim Pract 2007, 37:521-532.

25. Egenvall A, Bonnett BN, Olson P, Hedhammar $\AA$ : Validation of computerized Swedish dog and cat insurance data against veterinary practice records. Prev Vet Med 1998, 36:51-65.

26. Welsh S, Hassiotis A, O'Mahoney G, Deahl M: Big brother is watching you-the ethical implications of electronic surveillance measures in the elderly with dementia and in adults with learning difficulties. Aging Mental Health 2003, 7:372-375.

27. Wisniewski MF, Kieszkowski P, Zagorski BM, Trick WE, Sommers M, Weinstein RA: Development of a clinical data warehouse for hospital infection control. J Am Med Inform Assoc 2003, 10:454-462.

28. Koo D, Wharton M, Birkhead G: Case Definitions for Infectious Conditions Under Public Health Surveillance, US Department of Health and Human Services, Public Health Service, Centers for Disease Control and Prevention. Atlanta: Centers for Disease Control and Prevention; 1997.

29. Andresen EM, Catlin TK, Wyrwich KW, Jackson-Thompson J: Retest reliability of surveillance questions on health related quality of life. J Epidemio/ Community Health 2003, 57:339-343.

30. Buhi ER, Goodson P, Neilands TB: Out of Sight, Not Out of Mind, Strategies for Handling Missing Data. Am J Health Behav 2008, 32:83-92.

31. Bergen DC, Beghi E, Medina MT: Revising the ICD-10 codes for epilepsy and seizures. Epilepsia 2012, 53:3-5.

32. Haut ER, Pronovost PJ: SUrveillance bias in outcomes reporting. JAMA 2011, 305:2462-2463.

33. Nattinger $A B$, McAuliffe $T L$, Schapira MM: Generalizability of the surveillance, epidemiology, and end results registry population, Factors relevant to epidemiologic and health care research. J Clin Epidemiol 1997, 50:939-945

34. Galea S, Tracy M: Participation Rates in Epidemiologic Studies. Ann Epidemiol 2007, 17:643-653.

35. Schnitzer PG, Slusher P, Van Tuinen M: Child maltreatment in Missouri, Combining data for public health surveillance. Am J Prev Med 2004, 27:379-384.

36. Crompton P: The National Programme for Information Technology - an overview. J Vis Comm Med 2007, 30:72-77.

37. de Lusignan S: The barriers to clinical coding in general practice, A literature review. Inform Health Soc Care 2005, 30:89-97.

38. Mandl KD, Overhage JM, Wagner MM, Lober WB, Sebastiani P, Mostashari F, Pavlin JA, Gesteland PH, Treadwell T, Koski E, Hutwagner L, Buckeridge DL, Aller RD, Grannis S: Implementing syndromic surveillance, a practical guide informed by the early experience. J Am Med Inform Assoc 2004, 11:141-150.

39. Chaudhry B, Wang J, Wu S, Maglione M, Mojica W, Roth E, Morton SC, Shekelle PG: Systematic review, impact of health information technology on quality, efficiency, and costs of medical care. Ann Intern Med 2006, 144:742-752.

40. de Lusignan S, Krause P: The Hayes principles, learning from the national pilot of information technology and core generalisable theory in informatics. Inform Primary Care 2010, 18:73-77.

41. Howe D, Costanzo M, Fey P, Gojobori T, Hannick L, Hide W, Hill DP, Kania R, Schaeffer M, St Pierre S, Twigger S, White O, Yon RS: Big Data, the future of biocuration. Nature 2008, 455:47-50.

42. Melton GB, Hripcsak G: Automated detection of adverse events using natural language processing of discharge summaries. J Am Med Inform Assoc 2005, 12:448-457.

43. Chapman WW, Christensen LM, Wagner MM, Haug PJ, Ivanov O, Dowling JN, Olszewski RT: Classifying free-text triage chief complaints into syndromic categories with natural language processing. Artif Intell Med 2005, 33:31-40.

44. Woolhouse MEJ, Fèvre EM, Handel I, Heller J, Tildesley MJ, Parkin T, Reid SWJ: Guide to good practice for quantitative veterinary epidemiology. 2011:35.

45. Greenhall JE: Causes of insurance claims paid. Modern Veterinary Pract $1979,60: 853$. 
46. Asher L, Buckland E, Phylactopoulos CL, Whiting M, Abeyesinghe S, Wathes C: Estimation of the number and demographics of companion dogs in the UK. BMC Veterinary Res 2011, 7:74

47. VetCompass: VetCompass, Health surveillance for UK companion animals. London: RVC Electronic Media Unit; 2013. http://www.rvc.ac.uk/ VetCOMPASS/.

48. Agria Pet Insurance: Agria Pet Insurance. Agria Pet Insurance; 2013. http:// www.agriapet.co.uk

49. Egenvall A: Survey of the Swedish dog population, age, gender, breed, location and enrolment in animal insurance. Acta Veterinaria Scandinavica 1999, 40:231-240.

50. Perrin $\mathrm{T}$ : The business of urban animals survey, the facts and statistics on companion animals in Canada. The Canadian Veterinary Journal [La Revue Veterinaire Canadienne] 2009, 50:48-52.

51. Embrace Pet Insurance: Facts \& Statistics on the US Pet Insurance Industry. Embrace Pet Insurance; 2012. http://www.embracepetinsurance.com/aboutus/press/pet-insurance-statistics.aspx.

52. American Pet Products Association: Industry Statistics \& Trends. APPA; 2012 http://americanpetproducts.org/press_industrytrends.asp

53. Nødtvedt A, Guitian J, Egenvall A, Emanuelson U, Pfeiffer DU: The spatial distribution of atopic dermatitis cases in a population of insured Swedish dogs. Prev Veterinary Med 2007, 78:210-222.

54. Ioannidis JPA: Why most published research findings are false. PLoS Med 2005, 2:e124.

55. Bonnett $B N$, Egenvall $A$ : Age patterns of disease and death in insured Swedish dogs, cats and horses. J Comp Pathol 2010, 142:S33-S38.

56. Nødtvedt A, Bergvall K, Emanuelson U, Egenvall A: Canine atopic dermatitis, validation of recorded diagnosis against practice records in 335 insured Swedish dogs. Acta Veterinaria Scandinavica 2006, 48:8.

57. Egenvall A, Bonnett BN, Hedhammar A, Olson P: Mortality in over 350,000 insured Swedish dogs from 1995-2000, II. breed-specific age and survival patterns and relative risk for causes of death. Acta Veterinaria Scandinavica 2005, 46:121-136.

58. Dobson JM, Samuel S, Milstein H, Rogers K, Wood JLN: Canine neoplasia in the UK, estimates of incidence rates from a population of insured dogs. J Small Animal Pract 2002, 43:240-246.

59. Thrusfield MV: Demographic characteristics of the canine and feline populations of the UK in 1986. J Small Animal Pract 1989, 30:76-80.

60. Egenvall A, Bonnett BN, Olson P, Hedhammar Å: Gender, age, breed and distribution of morbidity and mortality in insured dogs in Sweden during 1995 and 1996. Veterinary Record 2000, 146:519-525.

61. Dixon S: Pet insurance, understanding the current state of play. Veterinary Business J 2012, 116:6-9.

62. Vilson $\AA$, Bonnett $B$, Hansson-Hamlin H, Hedhammar $\AA$ : Disease patterns in 32,486 insured German Shepherd Dogs in Sweden, 1995-2006. Veterinary Record 2013, 173:116.

63. Egenvall A, Nødtvedt A, Hv E: Bone tumors in a population of 400000 insured Swedish dogs up to 10 y of age, incidence and survival. Canadian J Veterinary Res 2007, 71:292-299.

64. Sallander M, Hedhammar $\AA$, Rundgren M, Lindberg JE: Demographic data of a population of insured Swedish dogs measured in a questionnaire study. Acta Veterinaria Scandinavica 2001, 42:71-80.

65. Fall $\mathrm{T}$, Hamlin $\mathrm{HH}$, Hedhammar $\AA$, Kämpe O, Egenvall A: Diabetes mellitus in a population of 180,000 insured dogs, incidence, survival, and breed distribution. J Veterinary Internal Med 2007, 21:1209-1216.

66. Bergstrom A, Nødtvedt A, Lagerstedt AS, Egenvall A: Incidence and breed predilection for dystocia and risk factors for cesarean section in a Swedish population of insured dogs. Veterinary Surg 2006 35:786-791.

67. Egenvall A, Bonnett BN, Haggstrom J: Heart disease as a cause of death in insured Swedish dogs younger than 10 years of age. J Veterinary Internal Med 2006, 20:894-903.

68. Bergknut N, Egenvall A, Hagman R, Gustås P, Hazewinkel HAW, Meij BP, Lagerstedt A: Incidence of intervertebral disk degeneration-related diseases and associated mortality rates in dogs. J Am Veterinary Med Assoc 2012, 240:1300-1309.

69. Edwards DS, Henley WE, Harding EF, Dobson JM, Wood JLN: Breed incidence of lymphoma in a UK population of insured dogs. Veterinary Comparative Oncology 2003, 1:200-206.

70. Egenvall A, Bonnett BN, Öhagen P, Olson P, Hedhammar $\AA$, von Euler $\mathrm{H}$ : Incidence of and survival after mammary tumors in a population of over
80,000 insured female dogs in Sweden from 1995 to 2002. Prev Veterinary Med 2005, 69:109-127.

71. Egenvall A, Bonnett BN, Shoukri M, Olson P, Hedhammar $\AA$, Dohoo I: Age pattern of mortality in eight breeds of insured dogs in Sweden. Prev Veterinary Med 2000, 46:1-14

72. Bonnett BN, Egenvall A, Olson P, Hedhammar $\AA$ : Mortality in insured Swedish dogs, rates and causes of death in various breeds. Veterinary Record 1997, 141:40-44.

73. Bonnett BN, Egenvall A, Hedhammar $\AA$, Olson P: Mortality in over 350,000 insured Swedish dogs from 1995-2000, I. breed-, gender-, age- and cause-specific rates. Acta Veterinaria Scandinavica 2005, 46:105-120.

74. Egenvall A, Hagman R, Bonnett BN, Hedhammar A, Olson P, Lagerstedt A: Breed risk of pyometra in insured dogs in Sweden. J Veterinary Internal Med 2001, 15:530-538.

75. VMDB: The Veterinary Medical Database. VMDB; 2013. http://www.vmdb. org/vmdbinfo.html

76. Fleming JM, Creevy KE, Promislow DEL: Mortality in North American dogs from 1984 to 2004, an investigation into age-, size-, and breed-related causes of death. J Veterinary Internal Med 2011, 25:187-198.

77. Wucherer KL, Wilke V: Thyroid cancer in dogs, an update based on 638 cases (1995-2005). J Am Animal Hospital Assoc 2010, 46:249-254.

78. Burkert BA, Kerwin SC, Hosgood GL, Pechman RD, Fontenelle JP: Signalment and clinical features of diskospondylitis in dogs, 513 cases (1980-2001). J Am Veterinary Med Assoc 2005, 227:268-275.

79. Hawkins EC, Basseches J, Berry CR, Stebbins ME, Ferris KK: Demographic, clinical, and radiographic features of bronchiectasis in dogs, 316 cases (1988-2000). J Am Veterinary Med Assoc 2003, 223:1628-1635.

80. Ward MP: Prevalence of and risk factors for leptospirosis among dogs in the United States and Canada, 677 cases (1970-1998). J Am Veterinary Med Assoc 2002, 220:53-58.

81. Gelatt KN, MacKay EO: Prevalence of the breed-related glaucomas in pure-bred dogs in North America. Veterinary Ophthalmol 2004, 7:97-111.

82. Ware WA, Hopper DL: Cardiac Tumors in Dogs, 1982-1995. J Veterinary Internal Med 1999, 13:95-103.

83. Zaninelli M, Campagnoli A, Reyes M, Rojas V: The O3-Vet project, Integration of a standard nomenclature of clinical terms in a veterinary electronic medical record for veterinary hospitals. Comput Methods Programs Biomed 2012, 108:760-772

84. SNOMED CT: Systematized Nomenclature of Medicine-Clinical Terms. International Health Terminology Standards Development Organisation; 2011. http://www.ihtsdo.org/snomed-ct/

85. Bellumori TP, Famula TR, Bannasch DL, Belanger JM, Oberbauer AM: Prevalence of inherited disorders among mixed-breed and purebred dogs, 27,254 cases (1995-2010). J Am Veterinary Med Assoc 2013, 242:1549-1555.

86. Dotson MJ, Hyatt EM: Understanding dog-human companionship. J Business Res 2008, 61:457-466.

87. Ward MP, Kelman M: Companion animal disease surveillance, A new solution to an old problem? Spatial Spatio-temporal Epidemiol 2011, 2:147-157.

88. Tobias KM, Rohrbach BW: Association of breed with the diagnosis of congenital portosystemic shunts in dogs, 2,400 cases (1980-2002). J Am Veterinary Med Assoc 2003, 223:1636-1639.

89. Green LW, Glasgow RE: Evaluating the relevance, generalization, and applicability of research. Evaluation Health Prof 2006, 29:126-153.

90. Holmes MA, Ramey DW: An introduction to evidence-based veterinary medicine. Veterinary Clinics of North America, Equine Practice 2007, 23:191-200.

91. Hill PB, Lo A, Eden CA, Huntley S, Morey V, Ramsey S, Richardson C, Smith DJ, Sutton C, Taylor MD, Thorpe E, Tidmarsh R, Williams V: Survey of the prevalence, diagnosis and treatment of dermatological conditions in small animals in general practice. Veterinary Record 2006, 158:533-539.

92. Chassin MR, Galvin RW: The urgent need to improve health care quality, Institute of Medicine national roundtable on health care quality. JAMA, The Journal of the American Medical Association 1998, 280:1000-1005.

93. Adams VJ, Waldner $\mathrm{CL}$, Campbell JR: Analysis of a practice management computer software program for owner compliance with recall reminders. The Canadian Veterinary Journal [La Revue Veterinaire Canadienne] 2006, 47:234-240.

94. Robinson D, Hooker H: The UK veterinary profession in 2006. London: Institute for Employment Studies; 2006.

95. RCVS: RCVS Facts 2012, Part 2. London: Royal College of Veterinary Surgeons; 2012. 28 p. 
96. Powell J, Buchan I: Electronic health records should support clinical research. J Med Internet Res 2005, 7:e4.

97. Hornof WJ, Brentson PR, Self JA, Ballance DW: Development of a complete electronic medical record in an academic institution. J Am Veterinary Med Assoc 2001, 218:1771-1775.

98. Estberg L, Case JT, Walters RF, Cardiff RD, Galuppo LD: Word search performance for diagnoses of equine surgical colics in free-text electronic patient records. Prev Veterinary Med 1998, 34:161-174.

99. Crowe DC: An appeal for better automated medical records. J Am Veterinary Med Assoc 2003, 223:1566-1567.

100. Lund EM, Klausner JS, Ellis LB, Whitney JR: PetTerms, a standardized nomenclature for companion animal practice. Online J Veterinary Res 1998, 2:64-86

101. Lund EM, Armstrong PJ, Kirk CA, Klausner JS: Prevalence and risk factors for obesity in adult cats from private US veterinary practices. Int I Appl Res Veterinary Med 2005, 3:88-96.

102. Lund EM, Armstrong PJ, Kirk CA, Klausner JS: Prevalence and risk factors for obesity in adult dogs from private US veterinary practices. Int J Appl Res Veterinary Med 2006, 4:177-186.

103. Rhea SK, Glickman SW, Waller A, Ising A, Maillard JM, Lund EM, Glickman LT: Evaluation of routinely collected veterinary and human health data for surveillance of human tick-borne diseases in North Carolina. Vector Borne and Zoonotic Diseases 2011, 11:9-14.

104. Anon: State of Pet Health 2013 Report. Banfield: Pet Hospital; 2013.

105. Plant JD, Lund EM, Yang M: A case-control study of the risk factors for canine juvenile-onset generalized demodicosis in the USA. Veterinary Dermatology 2011, 22:95-99.

106. Lefebvre SL, Yang M, Wang M, Elliott DA, Buff PR, Lund EM: Effect of age at gonadectomy on the probability of dogs becoming overweight. J Am Veterinary Med Assoc 2013, 243:236-243.

107. Moore GE, Guptill LF, Ward MP, Glickman NW, Faunt KK, Lewis HB, Glickman $L T$ : Adverse events diagnosed within three days of vaccine administration in dogs. J Am Veterinary Med Assoc 2005, 227:1102-1108.

108. Raghavan M, Glickman N, Moore G, Caldanaro R, Lewis H, Glickman L: Prevalence of and risk factors for canine tick infestation in the United States, 2002-2004. Vector Borne and Zoonotic Diseases 2007, 7:65-75.

109. Glickman LT, Glickman NW, Moore GE, Goldstein GS, Lewis HB: Evaluation of the risk of endocarditis and other cardiovascular events on the basis of the severity of periodontal disease in dogs. J Am Veterinary Med Assoc 2009, 234:486-494

110. Glickman LT: Association between chronic azotemic kidney disease and the severity of periodontal disease in dogs. Prev Veterinary Med 2011, 99:193-200.

111. Mohamed AS, Moore GE, Glickman LT: Prevalence of intestinal nematode parasitism among pet dogs in the United States (2003-2006). J Am Veterinary Med Assoc 2009, 234:631-637.

112. Lewis HB: Risk factors for canine pancreatitis. DataSavant November/ December, 17-22. ; 2007.

113. Lund E: Epidemiology of canine atopic dermatitis. Veterinary Focus 2011, 21:32-33.

114. Trevejo R, Yang M, Lund EM: Epidemiology of surgical castration of dogs and cats in the United States. J Am Veterinary Med Assoc 2011, 238:898-904.

115. Maciejewski R, Glickman N, Moore G, Zheng C, Tyner B, Cleveland W, Ebert $D$, Glickman L: Companion animals as sentinels for community exposure to industrial chemicals, the Fairburn, GA, propyl mercaptan case study. Public Health Reports 2008, 123:333-342.

116. Glickman L, Glickman N: The National Companion Animal Surveillance System NCASP. Purdue University; 2012. http://www.slideserve.com/noleta/thenational-companion-animal-surveillance-system-ncasp-a-supercourse-lecture

117. Glickman LT, Moore GE, Glickman NW, Caldanaro RJ, Aucoin D, Lewis HB: Purdue University-Banfield National Companion Animal Surveillance Program for emerging and zoonotic diseases. Vector Borne and Zoonotic Diseases 2006, 6:14-23.

118. Moore GE, Ward MP, Kulldorff M, Caldanaro RJ, Guptill LF, Lewis HB, Glickman LT: A space-time cluster of adverse events associated with canine rabies vaccine. Vaccine 2005, 23:5557-5562.

119. Thompson KA, Parnell NK, Hohenhaus AE, Moore GE, Rondeau MP: Feline exocrine pancreatic insufficiency, 16 cases (1992-2007) $\star$. J Feline Med Surg 2009, 11:935-940.
120. Brady S, Norris JM, Kelman M, Ward MP: Canine parvovirus in Australia, the role of socio-economic factors in disease clusters. Veterinary J 2012, 193:522-528.

121. Kearsley-Fleet L, O'Neill DG, Volk HA, Church DB, Brodbelt DC: Prevalence and risk factors for canine epilepsy of unknown origin in the UK. Veterinary Record 2013, 172:338.

122. O'Neill DG, Hendricks A, Summers J, Brodbelt DC: Primary care veterinary usage of systemic glucocorticoids in cats and dogs in three UK practices. J Small Animal Pract 2012, 53:217-222.

123. O'Neill DG, Church DB, McGreevy PD, Thomson PC, Brodbelt DC: Longevity and mortality of owned dogs in England. Veterinary J 2013, 198:638-643.

124. Wang X, Chase H, Markatou M, Hripcsak G, Friedman C: Selecting information in electronic health records for knowledge acquisition. $J$ Biomed Informatics 2010, 43:595-601.

125. Radford A: National surveillance of small animal disease in the UK. Veterinary Record 2010, 166:471-472.

126. BSAVA: SAVSNET The next stage. BSAVA Companion 2013:4-5.

127. Radford AD, Noble PJ, Coyne KP, Gaskell RM, Jones PH, Bryan JGE, Setzkorn C, Tierney Á, Dawson S: Antibacterial prescribing patterns in small animal veterinary practice identified via SAVSNET, the small animal veterinary surveillance network. Veterinary Record 2011, 169:310.

128. Pulley J, Clayton E, Bernard GR, Roden DM, Masys DR: Principles of human subjects protections applied in an opt-out, de-identified biobank. Clinical Translational Sci 2010, 3:42-48.

129. SAVSNET: SAVSNET. University of Liverpool; 2012. http://www.liv.ac.uk/ SAVSNET/

130. CEVM: Centre for Evidence-based Veterinary Medicine. Nottingham: University of Nottingham; 2013.

131. Clements D, Handel I, Rose E, Querry D, Pugh C, Ollier W, Morgan K, Kennedy L, Sampson J, Summers K, de Bronsvoort BM: Dogslife, a web-based longitudinal study of Labrador Retriever health in the UK. BMC Veterinary Res 2013 9:13.

132. Nakagawa S, Cuthill IC: Effect size, confidence interval and statistical significance, a practical guide for biologists. Biological Rev 2007, 82:591-605.

133. Schneeweiss S, Avorn J: A review of uses of health care utilization databases for epidemiologic research on therapeutics. J Clin Epidemiol 2005, 58:323-337.

134. David M, Ware R, Donald M, Alati R: Assessing generalisability through the use of disease registers, findings from a diabetes cohort study. $\mathrm{Br}$ Med $J$ Open 2011, 1:1-7.

135. Nødtvedt A, Berke O, Bonnett BN, Brønden L: Current status of canine cancer registration - report from an international workshop. Veterinary Comparative Oncol 2012, 10:95-101.

136. Parkin DM: The evolution of the population-based cancer registry. Nature Rev Cancer 2006, 6:603-612.

137. Brønden LB, Flagstad A, Kristensen AT: Veterinary cancer registries in companion animal cancer, a review. Veterinary Comparative Oncol 2007 5:133-144.

138. Michels GM, Knapp DW, DeNicola DB, Glickman N, Bonney P: Prognosis following surgical excision of canine cutaneous mast cell tumors with histopathologically tumor-free versus nontumor-free margins, a retrospective study of 31 cases. J Am Animal Hospital Assoc 2002, 38:458-466.

139. Cornell KK, Bostwick DG, Cooley DM, Hall G, Harvey HJ, Hendrick MJ, Pauli, BU, Render JA, Stoica G, Sweet DC, Waters DJ: Clinical and pathologic aspects of spontaneous canine prostate carcinoma, a retrospective analysis of 76 cases. Prostate 2000, 45:173-183.

140. Ru G, Terracini B, Glickman LT: Host related risk factors for canine osteosarcoma. Veterinary J 1998, 156:31-39.

141. Moe L: Population-based incidence of mammary tumours in some dog breeds. J Reprod Fertility Supp/ 2001, 57:439.

142. Støvring M, Moe L, Glattre E: A population-based case-control study of canine mammary tumours and clinical use of medroxyprogesterone acetate. APMIS 1997, 105:590-596.

143. Brønden LB, Nielsen SS, Toft N, Kristensen AT: Data from the Danish Veterinary Cancer Registry on the occurrence and distribution of neoplasms in dogs in Denmark. Veterinary Record 2010, 166:586-590.

144. Brønden L, Eriksen T, Kristensen AT: Mast cell tumours and other skin neoplasia in Danish dogs - data from the Danish Veterinary Cancer Registry. Acta Veterinaria Scandinavica 2010, 52:1-6. 
145. Vascellari M, Baioni E, Ru G, Carminato A, Mutinelli F: Animal tumour registry of two provinces in northern Italy, incidence of spontaneous tumours in dogs and cats. BMC Veterinary Res 2009, 5:39.

146. Merlo DF, Rossi L, Pellegrino C, Ceppi M, Cardellino U, Capurro C, Ratto A, Sambucco PL, Sestito V, Tanara G, Bocchini V: Cancer incidence in pet dogs, findings of the animal tumor registry of Genoa, Italy. J Veterinary Int Med 2008, 22:976-984.

147. Brønden LB, Lindstrand S, Nielsen SS, Toft N, Kristensen AT: Validation of data collected in the Danish Veterinary Cancer Registry. Veterinary Comparative Oncology 2009, 7:207-211.

148. Adams VJ, Evans KM, Sampson J, Wood JLN: Methods and mortality results of a health survey of purebred dogs in the UK. J Small Animal Pract 2010, 51:512-524.

149. PFMA: The Pet Food Manufacturers' Association 'Statistics'. The Pet Food Manufacturers' Association; 2012. http://www.pfma.org.uk/statistics/

150. Downes M, Canty MJ, More SJ: Demography of the pet dog and cat population on the island of Ireland and human factors influencing pet ownership. Prev Veterinary Med 2009, 92:140-149.

151. Casey RA, Loftus B, Bolster C, Richards GJ, Blackwell EJ: Inter-dog aggression in a UK owner survey, prevalence, co-occurrence in different contexts and risk factors. Veterinary Record 2013, 172:127.

152. Bland IM, Guthrie-Jones A, Taylor RD, Hill J: Dog obesity, owner attitudes and behaviour. Prev Veterinary Med 2009, 92:333-340.

153. Dufour S, Barkema HW, DesCôteaux L, DeVries TJ, Dohoo IR, Reyher K, Roy, J, Scholl DT: Development and validation of a bilingual questionnaire for measuring udder health related management practices on dairy farms. Prev Veterinary Med 2010, 95:74-85.

154. Dohoo I, Martin W, Stryhn H: Veterinary Epidemiologic Research. Charlottetown, Canada: VER Inc; 2009

155. Morton LM: Reporting participation in epidemiologic studies, a survey of practice. Am J Epidemiol 2006, 163:197-203.

156. van Gelder MMHJ, Bretveld RW, Roeleveld N: Web-based Questionnaires, The Future in Epidemiology? Am J Epidemiol 2010, 172:1292-1298.

157. Mellersh C: DNA testing, diagnosing and preventing inherited disorders in dogs. Veterinary Record 2013, 172:264-265.

158. Club TK: Assured Breeder Scheme. The Kennel Club: Breed-specific requirements and recommendations including health screening; 2012.

159. Gould D, Pettitt L, McLaughlin B, Holmes N, Forman O, Thomas A, Ahonen S, Lohi H, O'Leary C, Sargan D, Mellersh C: ADAMTS17 mutation associated with primary lens luxation is widespread among breeds. Veterinary Ophthalmol 2011, 14:378-384.

160. Mellersh C: DNA testing and domestic dogs. Mammalian Genome 2012, 23:109-123.

161. Strain GM: Aetiology, prevalence and diagnosis of deafness in dogs and cats. Br Veterinary J 1996, 152:17-36.

162. Wood JLN, Lakhani KH: Deafness in Dalmatians, does sex matter? Prev Veterinary Med 1998, 36:39-50.

163. De Risio L, Lewis T, Freeman J, de Stefani A, Matiasek L, Blott S: Prevalence, heritability and genetic correlations of congenital sensorineural deafness and pigmentation phenotypes in the Border Collie. Veterinary J 2011, 188:286.

164. Sommerlad S, Morton J, Haile-Mariam M, Johnstone I, Seddon J, O'Leary C: Prevalence of congenital hereditary sensorineural deafness in Australian Cattle Dogs and associations with coat characteristics and sex. BMC Veterinary Res 2012, 8:202.

165. Strain GM: Deafness prevalence and pigmentation and gender associations in dog breeds at risk. Veterinary J 2004, 167:23-32.

166. Crispin SM, Turner BM: Changes to the BVA/KC Canine Health Schemes. Veterinary Record 2010, 166:28.

167. Lewis TW: Optimisation of breeding strategies to reduce the prevalence of inherited disease in pedigree dogs. Animal Welfare 2010, 19:93-98.

168. Wilson B, Nicholas FW, Thomson PC: Selection against canine hip dysplasia, success or failure? Veterinary J 2011, 189:160-168.

169. Lewis TW: Genetic evaluation of hip score in UK Labrador Retrievers. PLoS One 2010, 5:1-10.

170. Lewis TW, Ilska JJ, Blott SC, Woolliams JA: Genetic evaluation of elbow scores and the relationship with hip scores in UK Labrador Retrievers. Veterinary J 2011, 189:227-233.

171. Dennis R: Interpretation and use of BVA/KC hip scores in dogs. Practice 2012, 34:178-194.
172. British Veterinary Association/Kennel Club/International Sheepdog Society: Eye Scheme. British Veterinary Association, 2013. http://www.bva.co.uk canine_health_schemes/Eye_Scheme.aspx

173. Crispin SM, Long SE, Wheeler CA: Incidence and ocular manifestations of multifocal retinal dysplasia in the Golden Retriever in the UK. Veterinary Record 1999, 145:669-672.

174. Long SE, Crispin SM: Inheritance of multifocal retinal dysplasia in the Golden Retriever in the UK. Veterinary Record 1999, 145:702-704.

175. Curtis R, Barnett KC: A survey of cataracts in Golden and Labrador Retrievers. J Small Animal Pract 1989, 30:277-286.

176. VMD: Veterinary Medicines Directorate: Suspected Adverse Events. Crown; 2012. http://www.vmd.defra.gov.uk/vet/adverse.aspx

177. Dyer F, Spagnuolo-Weaver M, Tait A: Suspected adverse reactions, 2005. Veterinary Record 2006, 158:464-466

178. Dyer F, Spagnuolo-Weaver M, Cooles S, Tait A: Suspected adverse reactions, 2006. Veterinary Record 2007, 160:748-750.

179. Dyer F, Spagnuolo-Weaver M, Coolees S, Tait A: Suspected adverse reactions, 2007. Veterinary Record 2008, 163:69-72.

180. Dyer F, Mulugeta R, Spagnuolo-Weaver M, Tait A: Suspected adverse reactions, 2004. Veterinary Record 2005, 156:561-563.

181. Dyer F, Diesel G, Cooles S, Tait A: Suspected adverse reactions, 2010. Veterinary Record 2011, 168:610-613.

182. Dyer F, Diesel G, Cooles S, Tait A: Suspected adverse events, 2011. Veterinary Record 2012, 170:640-642.

183. Dyer F, Diesel G, Cooles S, Tait A: Suspected adverse reactions, 2009. Veterinary Record 2010, 167:118-121.

184. Dyer F, Brown E, Cooles S, Tait A: Suspected adverse reactions, 2008. Veterinary Record 2009, 165:162-164.

185. Dyer E, Mulugeta R, Evans C, Tait A: Suspected adverse reactions, 2003. Veterinary Record 2004, 154:806-808.

186. DEFRA: Dog and Cat Travel And Risk Information (DACTARI). Crown; 2011. http://archive.defra.gov.uk/foodfarm/farmanimal/diseases/vetsurveillance/ dactari/summary-report.htm

187. Shaw SE, Langton DA, Hillman TJ: Canine leishmaniosis in the UK. Veterinary Record 2008, 163:253-254.

188. Anon: MSD Animal Health Intervet UK Ltd. ; 2013. http://www.msd-animalhealth.co.uk/

189. CICADA: CICADA - The companion animal disease survey. MSD Animal Health; 2012. http://uk.cicadasurvey.com/

190. Dórea FC, Sanchez J, Revie CW: Veterinary syndromic surveillance, current initiatives and potential for development. Prev Veterinary Med 2011, 101:1-17.

191. Stärk KD, Regula G, Hernandez J, Knopf L, Fuchs K, Morris RS, Davies P: Concepts for risk-based surveillance in the field of veterinary medicine and veterinary public health, review of current approaches. BMC Health Services Res 2006, 6:20

192. Stead WW, Miller RA, Musen MA, Hersh WR: Integration and Beyond, Linking Information from Disparate Sources and into Workflow. J Am Med Inf Assoc 2000, 7:135-145.

193. Egenvall A, Nødtvedt A, Roepstorff L, Bonnett B: Integrating databases for research on health and performance in small animals and horses in the Nordic countries. Acta Veterinaria Scandinavica 2011, 53:1-6.

194. British Veterinary Association/Kennel Club: Hip Dysplasia Scheme. British Veterinary Association; 2013. http://www.bva.co.uk/canine_health_schemes/ Hip_Scheme.aspx

195. British Veterinary Association/Kennel Club: Elbow Scheme. British Veterinary Association. 2013. http://www.bva.co.uk/canine health_schemes/ elbow_scheme.aspx

doi:10.1186/2052-6687-1-2

Cite this article as: O'Neill et al: Approaches to canine health surveillance. Canine Genetics and Epidemiology 2014 1:2. 